\title{
Analisis Derajat Kejenuhan dan Tingkat Pelayanan Jalan Sudiman Kota Pekanbaru
}

\author{
Khairulnas $^{1}$, Virgo Trisep Haris ${ }^{2}$, Winayati ${ }^{3}$. \\ Program Studi Teknik Sipil, Fakultas Teknik, Universitas Lancang Kuning \\ Jl. Yos Sudarso km. 8 Rumbai, Pekanbaru, Telp. (0761) 52324 \\ Email: surveyor_minang@yahoo.com, virgotrisepharis@gmail.com, winayatimt@gmail.com
}

\begin{abstract}
ABSTRAK
Jalan Sudirman Kota Pekanbaru adalah salah satu jalan yang mengalami aktifitas masyarakat yang disebabkan oleh adanya dua Mall dan padat pemukiman masyarakat. Terutama dalam hal urusan pemerintahan, pendidikan maupun ekonomi. Volume kendaraan yang melintasi jalan ini cukup padat sehingga menyebabkan terjadinya kemacetan berbagai jenis kendaraan yang melewati jalan ini mulai dari, sepeda motor, kendaraan ringan, dan kendaraan berat serta hambatan samping disepanjang jalan ini turut menyebabkan kepadatan arus lalu lintas terutama pada jam puncak, sehingga tingkat pelayanan jalan Sudirman Kota Pekanbaru tidak sebanding lagi melayani volume lalu lintas yang ada. Adapun rumusan dan tujuan dari penelitian ini untuk menghitung tingkat pelayanan jalan Sudirman Kota Pekanbaru saat ini. Jalan Sudirman Kota Pekanbaru merupakan tipe jalan dua lajur satu arah (2/1 UD). Dengan melakukan penelitian untuk mengetahui kondisi tingkat pelayanan jalan Sudirman pada saat ini. Analisis yang digunakan pada penelitian ini sesuai dengan analisis yang ada pada Manual Kapasitas Jalan Indonesia (MKJI) 1997. Sebelum melakukan analisis terlebih dahulu dilakukan survei lapangan dengan mengambil data diantaranya data geometri jalan, data lalu lintas, hambatan samping,dan kecepatan. Dari hasil analisis yang dilakukan, didapat DS sebesar 0,989, Kecepatan arus bebas sebesar 52,8 $\mathrm{km} / \mathrm{jam}$ dan Kapasitas jalan sebesar 5.742, smp/jam perjalur. Maka tingkat pelayanan jalan Sudirman Kota Pekanbaru termasuk tingkat pelayanan dengan karakteristik kondisi lalu lintas mencapai $1700 \mathrm{smp} / \mathrm{jam}$, satu arah kecepatan lalu lintas berkisar $60 \mathrm{~km} / \mathrm{jam}$.
\end{abstract}

Kata Kunci : Analisis, Jalan, Pelayanan

\begin{abstract}
Sudirman Road Pekanbaru City is one of the roads that experience the community activities caused by the existence of two malls and dense residential community. Especially in terms of government affairs, education and economics. The volume of vehicles crossing the road is quite dense, causing congestion of various types of vehicles passing through this road, from motorcycles, light vehicles and heavy vehicles and side barriers along the way, causing traffic congestion, especially at peak hours, Sudirman street service Pekanbaru city is no longer comparable to serving the volume of existing traffic. The formulation and purpose of this study to calculate the level of service Sudirman street Pekanbaru city today. Jalan Sudirman Pekanbaru is a two lane one way street (2/1 UD). By doing research to know condition of service level of Sudirman road at this time. The analysis used in this study is in accordance with the existing analysis on the Indonesian Road Capacity Manual (MKJI) 1997. Before conducting the first analysis conducted field survey by taking data such as road geometry data, traffic data, side barriers, and speed. From the results of the analysis, obtained DS of 0.989, free flow speed of $52.8 \mathrm{~km} / \mathrm{h}$ and the capacity of the road of 5.742, smp / hour of the road. So the level of service Sudirman Pekanbaru city including the level of service with the characteristics of traffic conditions reached 1700 smp / hour, one-way traffic speeds range $60 \mathrm{~km} / \mathrm{hour}$.
\end{abstract}

Keywords: Analysis, Road, Services

Khairulnas, Analisis Derajat Kejenuhan dan Tingkat Pelayanan Jalan Sudiman Kota Pekanbaru 


\section{Pendahuluan}

Kota Pekanbaru berkembang dengan pesat, dikawasan ini terdapat pusat perbelanjaan seperti Mall Pekanbanru, Senapelan Plaza, Hotel serta pemukiman penduduk yang padat. Ruas jalan Sudirman lebih padat oleh karena tingginya pengunjung. Selainitu, adanya pertumbuhan ekonomi penduduk sehingga meningkatkan aktifitas dan pergerakan masyarakat yang secara langsung berpengaruh pula pada kebutuhan akan kendaraan sebagai moda transportasi yang memadai untuk mengimbangi pertumbuhan kendaraan tersebut .

Jalan Sudirman adalah salah satu jalan yang mengalami peningkatan aktivitas masyarakat yang disebabkan oleh adanya dua Mall dan padat pemukiman masyarakat, yang menyebabkan terjadinya tarikan bagimasyarakat untuk dating keruas jalan Sudirman, sehingga rentan permasalahan lalulintas macet, tundaan, antrian. Kegiatan samping kanan - kiri jalan yang padat, perparkiran yang tidak memadai, peningkatan mobil pribadi, tingkah laku masyarakat penggunajalan yang tidak tertib, serta kendaraan yang masuk kepusat perbelanjaan yang menyebabkan terjadinya penurunan kecepatan lalulintas, dari hasil survey pendahuluan dilokasi tersebut didapat kecepatan rata - rata kendaraan 28 $\mathrm{km} / \mathrm{Jam}$, waktu tundaan yang terjadi mencapai 1 sampai 4 menit, kecepatan kendaraan dalam kota $\geq 40$ $\mathrm{km} / \mathrm{Jam}$. Berdasarkan peraturan Permenhub N0. 111 Tahun 2015

Peningkatan kapasitas jalan dapat menyelesaikan permasalahan diatas. Namun perludilakukan kajian terlebih dahulu perilaku karakteristik jalan seperti kecepatan kendaraan, volume lalulintas, dan kapasitas jalan tersebut. Salah satu indicator dari kinerja lalu lintas adalah derajat kejenuhan. Derajat kejenuhan (Ds) merupakan perbandingan antara volume lalulintas (V) dengan kapasitas jalan (C), besarnya yang secara teoritis antara 0 - 1 ,yang artinya jika nilai tersebut mendekati 1 maka kondisi jalan tersebut sudah mendekati jenuh. Hal ini didapat dari cukup padatnya volume kendaraan yang teradi di ruas jalan pada jam sibuk. Oleh karena itu, untuk menyelesai permasalahan ini di perlukan penelitian untuk mengetahui kapasitas jalan Sudirman guna mencari solusi atas kemacetan pada ruas jalan tersebut.

\section{METODE PENELITIAN}

Dalam suatu analisa maupun perencanaan transportasi, pengumpulan data merupakan salah satu tahapan yang sangat penting, tujuan dari tahap pengumpulan data dalam penelitian ini adalah untuk mendapatkan seluruh data mentah yang akan digunakan dalam analisis, data yang dikumpul kan dalam penelitian ini adalah data primer dan data sekunder, dan Sebelum melakukan survey untuk mendapatkan data secara lengkap dan akurat, Survey pendahuluan yang dilakukan bertujuan untuk mengetahui keadaan sekitar lokasi penelitian dan untuk memperkirakan titik - titik tempat pengamatan ditempatkan. Berdasarkan hasil survey pendahuluan yang dilakukan selama 1(Satu) hari, survey pendahuluan untuk penelitian ini adalah survei kondisi jalan dalam melayani arus lalu lintas yang digunakan sabagai dasar untuk menentukan tingkat pelayanan jalan. Dari hasil survei pendahuluan, diperoleh kondisi arus lintas pada jam - jam sibuk sebagai berikut :

1. Siang hari, pukul $10.00-13.00 \mathrm{WIB}$

2. Sore hari, pukul $16.00-18.00$ WIB

Survei dilakukan untuk mengumpulkan data primer berupa waktu perjalanan bus dari pandau ke pelita pantai, perjalanan bus dari pelita pantai ke pandau dan menghitung jumlah penumpang perjam. Metode pelaksanaan pengambilan data pada saat survei adalah sebagai berikut:

1. Data geometrikjalan

Pengumpulan data geometrik jalan dilakukan dengan mengukur segmen jalan, lebar jalur masing - masing sisi median serta bahu jalan.

2. Data lalu lintas

Pada saat pengambilan data kendaraan ringan, berat serta sepeda motor surveyor diletakkan pada dua sisi jalan. Sisi pertama surveyor diletakkan pada ruas Jalan Sudirman di depan Mall Pekanbaru dan sisi kedua diletakkan pada ruas Jalan Sudirmanmenujukejalanarahbandara, dengan jumlah surveyor 3 orang. Survey untuk masing - masing Kendaraan seperti kendaraan ringan (LV), kendaraan berat (HV) dan kendaraan bermotor (MC) dibagi menjadi 2 orang/jenis kendaraan.

3. Hambatan samping

Pada saat pengambilan data hambatan samping surveyor berjumlah 1 orang, dengan posisi surveyor berada di tengah-tengah lokasi penelitian, yaitu disebelah jalan masuk Mall Pekanbaru.

4. Survey kecepatan

Survey kecepatan diambil pada jarak 200 m, dengan cara mengambil 3 data kecepatan yaitu pada kondisi arus bebas, normal dan padat. Survei kecepatan dilakukan dengan menggunakan 2 orang untuk mengambil waktu tempuh kendaraan, orang pertama berada di Sta 0 dan org kedua berada di Sta $0+200$, orang yang berada di Sta 0 memberi kode kendaraan yang akan menjadi acuan org yang berada di Sta 0+200 menekan stopwatch untuk mengembil kecepatan tersebut, ketika kendaraan tersebut mencapai Sta $0+200$ stopwatch tersebut 
dihentikan, maka itulah yang dijadikan sebagai waktu tempuh kendaraan.

\section{Alat Yang Digunakan}

1. Kalkulator untuk perhitungan data survei dilapangan

2. Alat tulis untuk mencatat hasil survey dilapangan

3. Stopwactch untuk menghitung kecepatan sementara

4. Meteran untuk menghitung lebar jalan

5. Kamera untuk dokumentasi lapangan

\section{Bagan Alir Penelitian}

Bagan alir penelitian mengenai analisis drajat kejenuhan dan tingkat pelayanan jalan sudirman kota pekanbaru

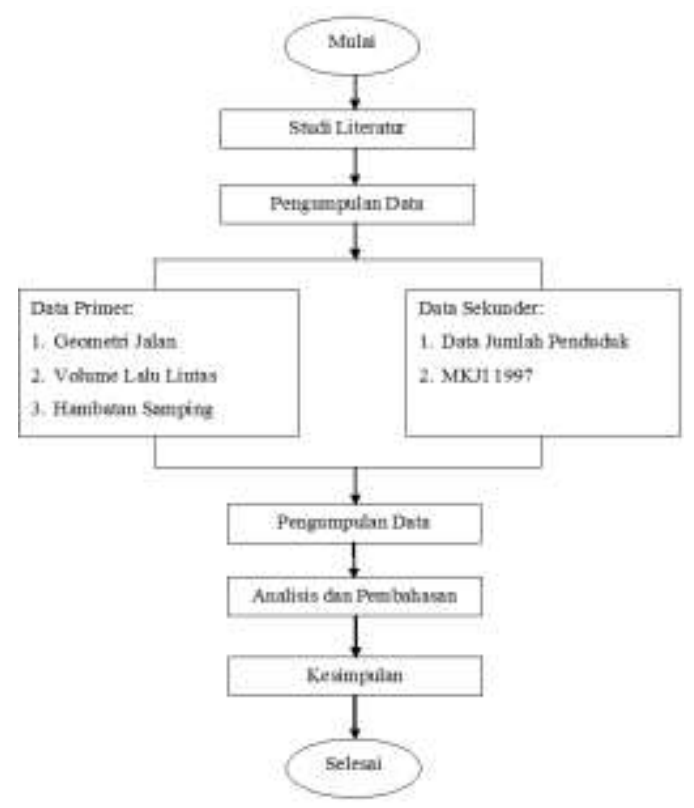

Gambar 1. Diagram alir pembuatan bata ringan

\section{HASIL DAN PEMBAHASAN}

\section{Data Primer}

Pengambilan data survey lalu lintas ini dilakukan selama tujuh hari yakni dimulai pada hari selasa tanggal 27Maret2018 sampai hari senin tanggal 02april2018. Adapun data tabel 4.2merupakan data survei lalu lintas pada hari sabtu yang merupakan data lalu lintas maksimal/puncak selama satu minggu.

Tabel 4.1 Geometrik jalan Riau kota Pekanbaru

\begin{tabular}{|c|c|}
\hline Geometrik Jalan & Empat 1ajur terbagi (4/2 D) \\
\hline Lebar Jalur & 7 meter \\
\hline Lebar bahu & 5.5 meter \\
\hline Median & 2.5 meter \\
\hline Trotoar & 5 meter \\
\hline Jalur Hijau & Tidak ada \\
\hline Saluran & Tidak ada \\
\hline
\end{tabular}

( Sumber : Data hasil survei, 2018)

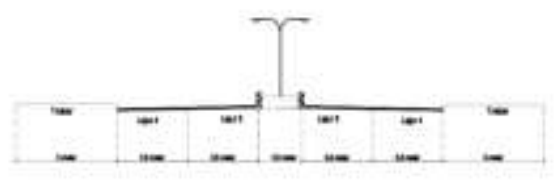

Gambar 4.1 Potongan melintang jalanSudirman (Sumber: Data hasil survei, 2018)

Table 1. data jumlah penumpang maksimum trayek pandau pelita pantai pada hari selasa tanggal 3 april 2018

\begin{tabular}{|c|c|c|c|c|c|}
\hline \multirow{2}{*}{ Hari } & \multirow{2}{*}{ Waktu } & \multicolumn{4}{|c|}{ IL. Sudinman-Bandura } \\
\hline & & L.V & HV & $\mathrm{MC}$ & Jumlat \\
\hline \multirow{12}{*}{ Sabtie } & $06.00-07.00$ & 851 & 17 & 723 & 1.591 \\
\hline & $07.00-08.00$ & 1,083 & 20 & 298 & $201 \mathrm{t}$ \\
\hline & $08.00 \cdot 09.00$ & 1,436 & 21 & 1,154 & 2,611 \\
\hline & $09.00-10.00$ & 1,399 & 19 & 1,256 & 2.674 \\
\hline & $10.00-11.00$ & 1,504 & 20 & 1,467 & 2901 \\
\hline & $11.00-12.00$ & 1,664 & 23 & 1.765 & 3,452 \\
\hline & $12.00-13.00$ & 1,817 & 21 & 1,678 & 3,516 \\
\hline & $13.00-14.00$ & 1,932 & 20 & 1,723 & 3.655 \\
\hline & $14.00-15.00$ & 2036 & 20 & 1. $69 \mathrm{~s}$ & 3,754 \\
\hline & $15.00-16.00$ & 2.140 & 19 & 1,865 . & 4024 \\
\hline & $16.00-17.00$ & 2,282 & 21 & 2,124 & 4,427 \\
\hline & $17.00-18.00$ & 2011 & 21 & 1.969 & 4,021 \\
\hline \multicolumn{2}{|c|}{ hamilet per hari } & 20.165 & 242 & 18,340 & 38.747 \\
\hline \multicolumn{2}{|c|}{ Total 2Arah } & & & & \\
\hline \multicolumn{2}{|c|}{ 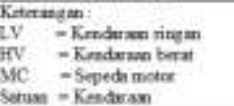 } & & & & \\
\hline
\end{tabular}

(Sumber: Data hasil survei, 2018)

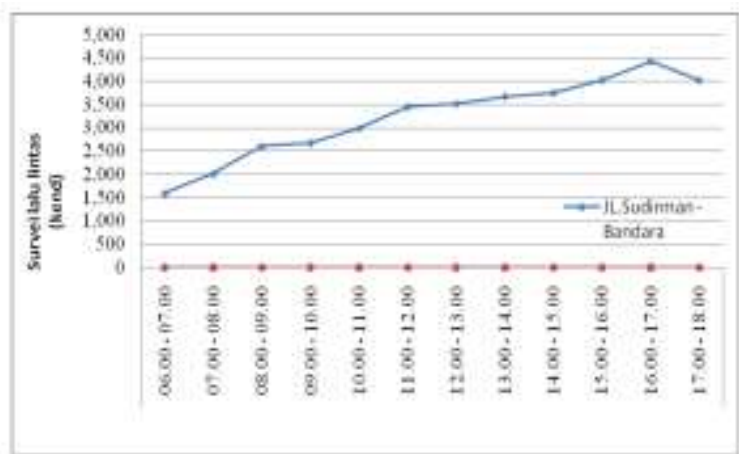

Gambar 4.2 Grafik data hasil survei lalu lintas jalan Sudirman depan Mall Pekanbaru (Sumber:Datahasil survei,2018)

\section{Analisis volume lalu lintas}

Arus lalu lintas (Q) dalam setiap pergerakan dinyatakan dalam satuan mobil penumpang (smp) perjam dengan ekivalen mobil penumpang yang berbeda berdasarkan jenis kendaraannya yang dapat dilihat pada tabel 2.3 dimana data yang digunakan yakni data untuk tipe jalan Dua lajur satu arah (2/1 
UD), dengan arus lalu lintas total satu arah diubah menjadi satuan mobil penumpang (smp).

Berikut ini adalah salah satu contoh perhitungan volume lalu lintas berdasarkan data survei maksimum pada hari sabtu pukul $16.00 \mathrm{~s} / \mathrm{d}$ 17.00 WIB dari arahJalan Sudirman - Bandarasebagai berikut:

$\begin{array}{ll}\text { LV } & =2282 \\ \text { emp LV } & =1,0 \\ \text { HV } & =21 \\ \text { Emp HV } & =1,2 \\ \text { MC } & =2124 \\ \text { Emp MC } & =0,25\end{array}$

$\mathrm{Q}=(\mathrm{LV} \times \mathrm{emp})+(\mathrm{HV} \times \mathrm{emp})+(\mathrm{MC} \times \mathrm{emp})$

$=(2.282 \times 1,0)+(21 \times 1,2)+(2.124 \times 0,25)$

$=2.838 \mathrm{smp} / \mathrm{jam}$

\section{Data waktu tempuh}

Hasil perhitungan volume lalu lintas untuk perhitungan selanjutnya dapat dilihat pada tabel 4.3 dan hasil perhitungan volume lalu lintas hari-hari lain dapat dilihat pada lampiran 2 .

Tabel 4.3Hasil perhintungan volume lalu lintas jalan Sudirman depan Mall Pekanbaru

\begin{tabular}{|c|c|c|c|c|c|c|c|c|c|c|c|}
\hline \multirow{5}{*}{ Hari } & \multirow{5}{*}{ Waktu } & \multicolumn{10}{|c|}{ JL.Sudirman - Bandara } \\
\hline & & \multicolumn{3}{|c|}{ Kendaraan ringan } & \multicolumn{3}{|c|}{ Kendaraan berat } & \multicolumn{3}{|c|}{ Sepeda motor } & \multirow[t]{2}{*}{ Jumlah } \\
\hline & & \multirow{2}{*}{ LV } & \multirow{2}{*}{$\frac{\text { emp }}{(1,0)}$} & \multirow{2}{*}{ smpliam } & \multirow{2}{*}{ HV } & emp & \multirow{2}{*}{ smpljam } & \multirow{2}{*}{ MC } & \multirow{2}{*}{$\begin{array}{l}\text { emp } \\
(0,2) \\
\end{array}$} & \multirow{2}{*}{ smpljam } & \\
\hline & & & & & & $(1,2)$ & & & & & perjam. \\
\hline & & a & b & $c=2 x b$ & d & & $\mathrm{f}=\mathrm{dxe}$ & $\mathrm{g}$ & $\mathrm{h}$ & $i=g x h$ & \\
\hline \multirow{12}{*}{ Sabtu } & $06.00-07.00$ & 851 & 1 & 851 & 17 & 1.2 & 20.4 & 723 & 0.25 & 180.75 & 1052.2 \\
\hline & $07.00-08.00$ & 1093 & 1 & 1093 & 20 & 1.2 & 24 & 898 & 0.25 & 224.5 & 1341.5 \\
\hline & $08.00-09.00$ & 1436 & 1 & 1436 & 21 & 1.2 & 25.2 & 1154 & 0.25 & 288.5 & \begin{tabular}{|l|l|}
1749.7 \\
\end{tabular} \\
\hline & $09,00-10.00$ & 1399 & 1 & 1399 & 19 & 1.2 & 22.8 & 1256 & 0.25 & 314 & 1735.8 \\
\hline & $10.00-11.00$ & 1504 & 1 & 1504 & 20 & 1.2 & 24 & 1467 & 0.25 & 366.75 & 1894.8 \\
\hline & $11.00-12.00$ & 1664 & 1 & 1664 & 23 & 1.2 & 27.6 & 1765 & 0.25 & 441.25 & 2132.9 \\
\hline & $12.00-13.00$ & 1817 & 1 & 1817 & 21 & 1.2 & 25.2 & 1678 & 0.25 & 419.5 & 2261.7 \\
\hline & $13.00-14.00$ & 1932 & 1 & 1932 & 20 & 1.2 & 24 & 1723 & 0.25 & 430.75 & 2386.8 \\
\hline & $14.00-15.00$ & 2036 & 1 & 2036 & 20 & 1.2 & 24 & 1698 & 0.25 & 424.5 & 2484.5 \\
\hline & $15.00-16.00$ & 2140 & 1 & 2140 & 19 & 1.2 & 22.8 & 1865 & 0.25 & 466.25 & 2629.1 \\
\hline & $16.00-17.00$ & 2282 & 1 & 2282 & 21 & 1.2 & 25.2 & 2124 & 0.25 & 531 & 2838.2 \\
\hline & $17.00-18.00$ & 2011 & 1 & 2011 & 21 & 1.2 & 25.2 & 1989 & 0.25 & 497.25 & 2533.5 \\
\hline \multicolumn{2}{|c|}{ Jumlah per hari } & & & 20165 & & & 200.4 & & & 4585 & \\
\hline \multicolumn{2}{|c|}{ Total 1 Arah } & & & & & & & & & & $25040 \mid$ \\
\hline
\end{tabular}

(Sumber: Hasil perhitungan, 2018)

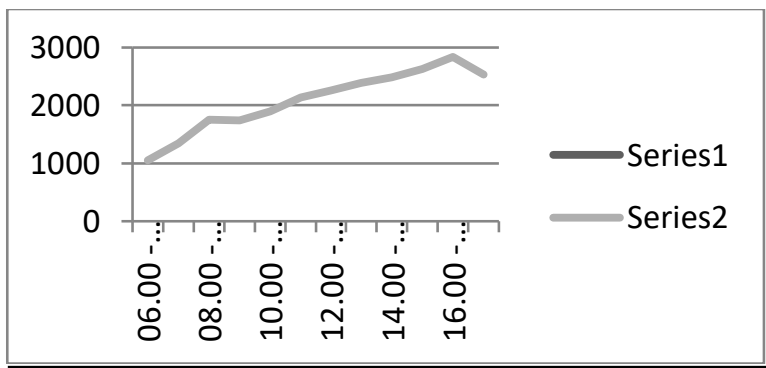

Gambar 4.3 Grafik hasil perhitunganvolume lalu lintasjalanSudirman di depan Mall Pekanbaru (Sumber: Data hasil survei, 2018)
Tabel 4.4 Data survey hambatan samping jalan Sudirman di depan Mall Pekanbaru

\begin{tabular}{|c|c|c|c|c|}
\hline \multirow[b]{2}{*}{ Waktu } & \multicolumn{4}{|c|}{ JL.Sudirman - Bandara } \\
\hline & PSV & EEV & SMV & Jumlah \\
\hline 1 & 2 & 3 & 4 & 5 \\
\hline $06.00-07.00$ & 12 & 80 & 43 & 135 \\
\hline $07.00-08.00$ & 26 & 106 & 56 & 188 \\
\hline $08.00-09.00$ & 29 & 179 & 73 & 281 \\
\hline $09.00-10.00$ & 34 & 246 & 132 & 412 \\
\hline $10.00-11.00$ & 54 & 303 & 115 & 472 \\
\hline $11.00-12.00$ & $\overline{72}$ & 372 & 167 & 611 \\
\hline $12.00-13.00$ & $\overline{61}$ & 402 & 198 & 661 \\
\hline $13.00-14.00$ & 67 & 397 & 223 & 687 \\
\hline $14.00-15.00$ & 58 & 402 & 241 & 701 \\
\hline $15.00-16.00$ & 63 & 458 & 276 & 797 \\
\hline $16.00-17.00$ & 74 & 551 & 267 & 892 \\
\hline $17.00-18.00$ & 63 & 510 & 234 & 807 \\
\hline Jumlah & 613 & 4006 & 2025 & 6644 \\
\hline \multicolumn{5}{|l|}{ Total Per Hari } \\
\hline \multicolumn{5}{|l|}{ Keterangan : } \\
\hline \multicolumn{5}{|c|}{$=$ Pejalan kaki $(0)$} \\
\hline \multicolumn{5}{|c|}{$=$ Parkir, kendaraan berhenti } \\
\hline \multicolumn{5}{|c|}{$=$ Kendaraan masuk + keluar } \\
\hline \multicolumn{5}{|c|}{ = Kendaraan lambat } \\
\hline \multicolumn{5}{|c|}{ = Kejadian } \\
\hline
\end{tabular}

(sumber: data hasil survei, 2018)

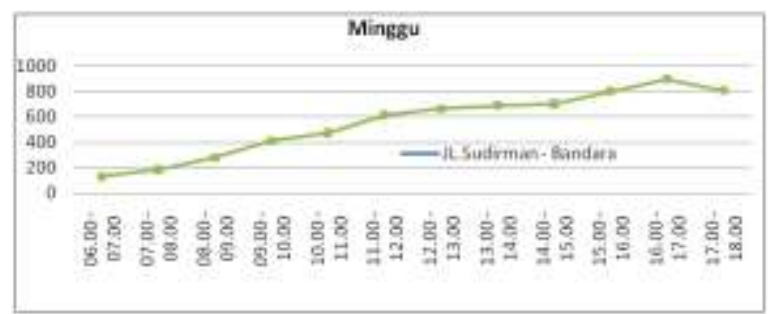

Gambar 4.4 Grafik data hasil survei hambatan samping jalan Sudirman depan Mall Pekanbaru (Sumber:Data hasil survey 2018)

\section{Analisis hambatan samping}

Berikut ini merupakan contoh perhitungan analisis frekuensi hambatan samping berdasarkan data survei maksimum pada hari Minggu pukul $17.00 \mathrm{~s} / \mathrm{d}$ 18.00 WIB dari arah jalan Sudirman - Bandara adalah sebagai berikut:

$\begin{array}{ll}\text { PED } & =0 \\ \text { f.bobot } & =0,5 \\ \text { PSV } & =63 \\ \text { f.bobot } & =1,0 \\ \text { EEV } & =510 \\ \text { f.bobot } & =0,7 \\ \text { SMV } & =234 \\ \text { f.bobot } & =0,4\end{array}$

Frekuensi hambatan samping

$$
\begin{aligned}
= & (\text { PED } \times \text { f.bobot })+(\text { PSV } \times \text { f.bobot })+ \\
& (\text { EEV x f.bobot })+(\text { SMV x f.bobot }) \\
= & (0 \times 0,5)+(63 \times 1,0)+(510 \times 0,7)+(234 \times \\
& 0,4) \\
= & 513.6 \text { kejadian/jam } / 200 \text { meter }
\end{aligned}
$$


Tabel 4.5 frekuensi hambatan samping

\begin{tabular}{|c|c|c|}
\hline \multirow{2}{*}{ Waktu } & JL.Sudirman - Bandara & \multirow{2}{*}{ Jumlah 1 Arah } \\
\cline { 2 - 2 } & Jumlah & 85 \\
\hline $06.00-07.00$ & 85 & 123 \\
\hline $07.00-08.00$ & 123 & 184 \\
\hline $08.00-09.00$ & 184 & 259 \\
\hline $09.00-10.00$ & 259 & 312 \\
\hline $10.00-11.00$ & 312 & 399 \\
\hline $11.00-12.00$ & 399 & 422 \\
\hline $12.00-13.00$ & 422 & 434 \\
\hline $13.00-14.00$ & 434 & 436 \\
\hline $14.00-15.00$ & 436 & 494 \\
\hline $15.00-16.00$ & 494 & 567 \\
\hline $16.00-17.00$ & 567 & 514 \\
\hline $17.00-18.00$ & 514 & 4,227 \\
\hline \multicolumn{2}{|c|}{ Total per hari } \\
\hline
\end{tabular}

(Sumber: Hasil perhitungan 2018)

Gambar 4.5 Grafik hasil perhitunganhambatan samping jalan Sudirman - Bandara

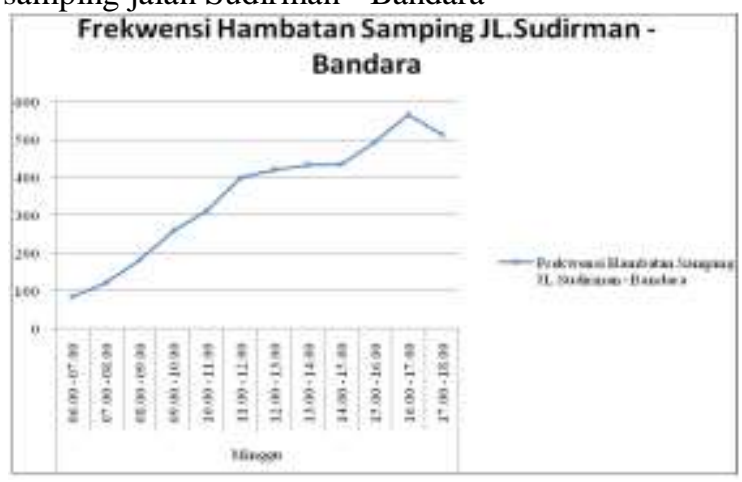

(Sumber: Data hasil survei, 2018)

\section{Analisis kapasitas jalan}

Perhitungan analisis kapasitas jalan adalah sebagai berikut:

$$
\begin{aligned}
\mathrm{C} & =\mathrm{Co} \times \mathrm{FCW} \times \mathrm{FCSP} \times \mathrm{FCSF} \times \mathrm{FCCS} \\
& =3.300 \times 2,00 \times 1,00 \times 0,87 \times 1,00 \\
& =5.742 \mathrm{smp} / \mathrm{jam}
\end{aligned}
$$

Berdasarkan hasil perhitungan diatas maka kapasitas jalan Sudirman kota Pekanbaru sebesar 5.742 smp/jam untuk 2 lajur 1 arah, sementara untuk satu lajur jalan kapasitas jalan sebesar 5.742/2 = 2871 smp/jam.

Keterangan :

Untuk nilai Co $\quad=3.300$ adalah $1650 \times 2=3.300$

Untuk nilai FCW $=2$ adalah $1.00 \times 2=2.00$

\section{Analisis derajat kejenuhan}

Berikut ini merupakan contoh perhitungan derajat kejenuhan pada hari Sabtu berdasarkan data maksimal pada hari Sabtu pukul 16.00 s/d 17.00 WIB dari arah Jalan Sudirman - Bandaraadalah sebagai berikut:

$$
\begin{aligned}
\mathrm{Q} & =2.838 \mathrm{smp} / \mathrm{jam} \\
\mathrm{C} & =2871 \mathrm{smp} / \mathrm{jam} \\
\mathrm{DS} & =\mathrm{Q} / \mathrm{C} \\
& =2.838 / 2871 \\
& =0,989
\end{aligned}
$$

\begin{tabular}{|c|c|c|}
\hline \multirow{2}{*}{ Waktu } & Arah & JL.Sudirman - Bandara \\
\hline & Hari & Sabtu \\
\hline $06.00-07.00$ & \multirow{12}{*}{ DS rata-rata } & 0.366 \\
\hline $07.00-08.00$ & & 0.467 \\
\hline $08.00-09.00$ & & 0.609 \\
\hline $09.00-10.00$ & & 0.605 \\
\hline $10.00-11.00$ & & 0.66 \\
\hline $11.00-12.00$ & & 0.743 \\
\hline $12.00-13.00$ & & 0.788 \\
\hline $13.00-14.00$ & & 0.831 \\
\hline $14.00-15.00$ & & 0.865 \\
\hline $15.00-16.00$ & & 0.916 \\
\hline $16.00-17.00$ & & 0.989 \\
\hline $17.00-18.00$ & & 0.882 \\
\hline \multicolumn{2}{|c|}{ Rata-ric } & 0.727 \\
\hline
\end{tabular}

Tabel 4.6 Hasil analisis derajat kejenuhan JL. Sudirman - Bandara

(Sumber: Hasil perhitungan, 2018)

Gambar 4.6 Grafik hasil perhitungan derajat kejenuhanjalan Sudirman - Bandara

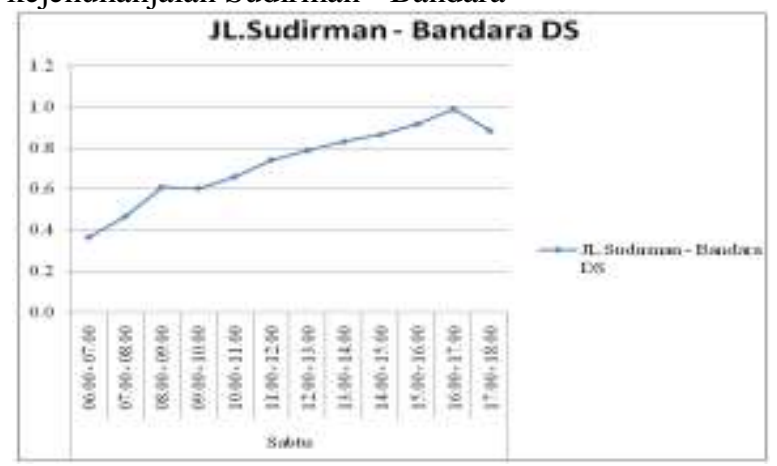

(Sumber: Data hasil survei, 2018)

\section{Data waktu tempuh arus bebas dilapangan}

Berdasarkan hasil survei dilapangan, maka diperoleh lama waktu tempuh yang dibutuhkan oleh kendaraan untuk menempuh JL.Sudirman Bandaradengan panjang jalan yang diamati $\pm 200 \mathrm{~m}$ adalah sebagai berikut:

Tabel 4.7 Waktu tempuh arus bebas dan padat dilapanganJL.Sudirman - Bandara

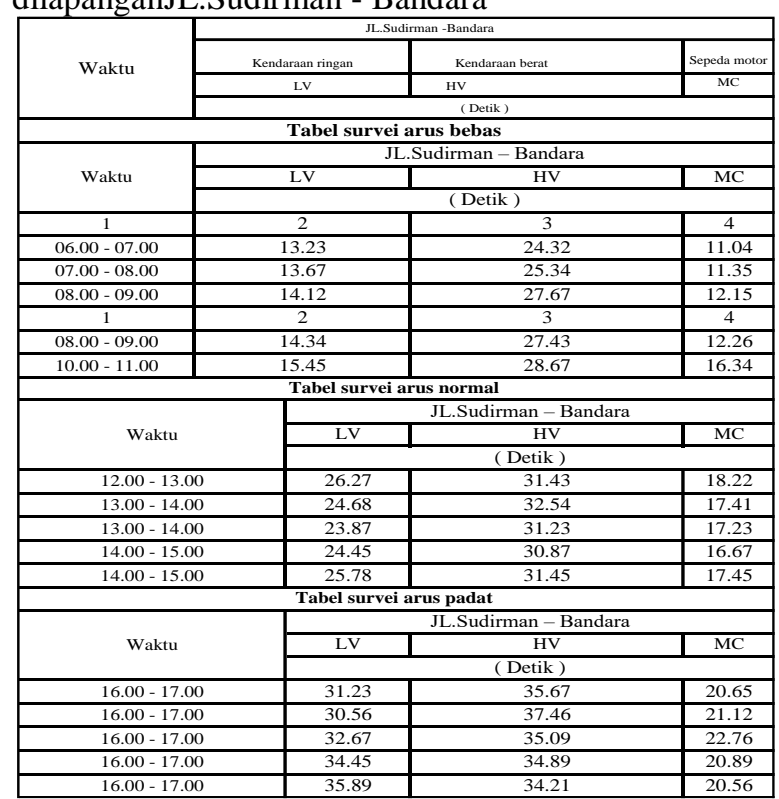

(Sumber: Data hasil survei, 2018) 


\section{Analisis kecepatan arus bebas}

Berdasarkan MKJI bahwa kecepatan arus bebas kendaraan ringan digunakan sebagai ukuran utama kinerja jalan. Berikut ini contoh perhitungan kecepatan arus bebas :

$$
\begin{aligned}
\text { FVo } & =55(\mathrm{~km} / \mathrm{jam}) \\
\text { FVw } & =0(\mathrm{~km} / \mathrm{jam}) \\
\text { FFVSF } & =0,96 \\
\text { FFVCS } & =1,00 \\
\mathrm{FV} & =(\mathrm{FVO}+\mathrm{FVW}) \times \text { FFVSF } \times \text { FFVCS } \\
& =(55+0) \times 0,96 \times 1,00 \\
& =52.8 \mathrm{~km} / \mathrm{jam}
\end{aligned}
$$

Gambar 4.7 Grafik fungsi derajat kejenuhan arah JL.Sudirman - Bandara

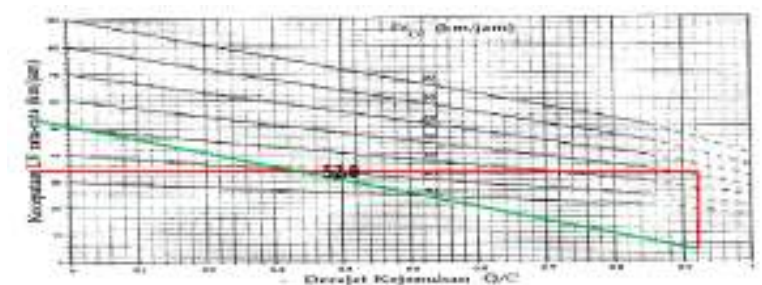

(Sumber : Hasil perhitungan, 2018)

Berdasarkan hasil perhitungan sebelumnya didapat : Kecepatan arus bebas (FV) $\quad=52.8 \mathrm{~km} / \mathrm{jam}$ (berdasarkan perhitungan)

Derajat kejenuhan (DS) $=0,989$ (berdasarkan tabel 4.6)

Maka dengan menggunakan grafik fungsi derajat kejenuhan (DS) didapat :

Kecepatan rata-rata kendaraan ringan $= \pm 25,92$ $\mathrm{km} / \mathrm{jam}$

Berikut ini merupakan contoh perhitungan kecepatan arus bebas berdasarkan survey dilapangan dengan panjang jalan yang diamati $\pm 200 \mathrm{~m}$ dari Jalan Sudirman - Bandara pada jam 06.00-07.00 WIB sebagai berikut:

$$
\begin{array}{ll}
\mathrm{S} & =200 \mathrm{~m}=0,2 \mathrm{~km} \\
\mathrm{~T} & =13,23 \operatorname{detik}: 3600=0,003675 \mathrm{jam} \\
\mathrm{V} & =\mathrm{S} / \mathrm{T}=0,2 / 0,003675=54.421 \mathrm{~km} / \mathrm{jam}
\end{array}
$$

Tabel 4.8 Kecepatan arus bebas dan padat berdasarkan survey dilapangan

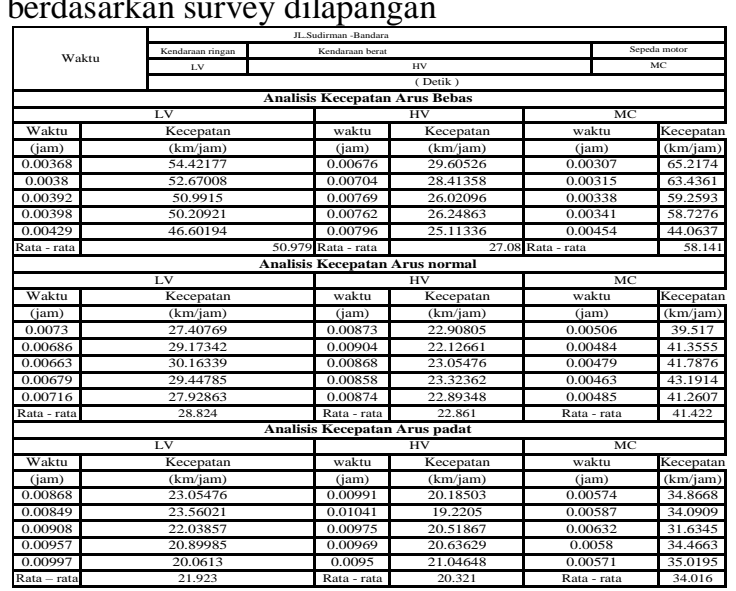

(Sumber: Data hasil survei, 2018)
Dari tabel diatas, maka diperoleh kecepatan arus bebas kendaraan ringanrata-rata berdasarkan survey dilapangan sebesar $54,421 \mathrm{~km} / \mathrm{jam}$ dari arah Jalan Sudirman - Bandara, untuk kecepatan pada saat arus normal rata-rata berdasarkan survei dilapangan sebesar27,407 km/jam dari arah Jalan Sudirman Bandara, Sedangkan untuk kecepatan pada saat arus padat rata-rata berdasarkan survei dilapangan sebesar 23,054 km/jam dari arah Jalan Sudirman - Bandara.

Dari hasil perhitungan - perhitungan diatas, dapat diketahui DS sebesar 0,989, Kecepatan arus bebas kendaraan sebersar 52,8 km/jam dan kapasitas jalan sebesar5.742smp/jam perjalur. Berdasarkan table 2.17, maka jalan Sudirman termasuk tingkat pelayanan D dengan, karakteristik kondisi lalu lintas mencapai $1700 \mathrm{smp}$ perjam, 1 arah kecepatan lalu lintas berkisaran $60 \mathrm{~km} / \mathrm{jam}$.

\section{Pembahasan}

Berdasarkan hasil analisis yang diawali dengan survey pendahuluan pada jam-jam sibuk sebagai berikut :

3. Pagi hari, pukul 06.00-08.00 WIB

4. Siang hari, pukul $11.30-13.00 \mathrm{WIB}$

5. Sore hari, pukul $16.00-18.00 \mathrm{WIB}$

Berdasarkan hasil survei dilapangan selama 7 hari, dimulai pada hari selasa tanggal 27 Maret 2018 sampai hari senin tanggal 02 April 2018, dan dimulai pada pukul jam 06.00-18.00 WIB.untuk mengumpulkan data primer, mulai dari geometrik jalan, data lalu lintas, data hambatan samping dan survey kecepatan, dengan jumlah surfay 8 orang. Survey untuk masing - masing Kendaraan seperti kendaraan ringan (LV), kendaraan berat (HV) dan kendaraan bermotor (MC) dibagi menjadi 2 orang/jenis kendaraan.

Pada saat menganalisis derajat kejenuhan dan tingkat pelayanan jalan Sudirmankota Pekanbaru acuan yang digunakan adalah MKJI, 1997, dengan menggunakan data volume lalu lintas maksimal/jam puncak yaitu pada hari Sabtu pukul 16.00 s/d 17.00 WIB, dan menggunakan data hambatan samping maksimal/jam puncak pada hari minggu 30 Maret 2018 pada pukul $16.00-17.00$ WIB,maka dapat diketahui bahwa derajat kejenuhan sebesar 0,989, kecepatan arus bebas sebesar $60 \mathrm{~km} / \mathrm{jam}$ dan kapasitas jalan sebesar 5.742 smp/jam, berdasarkan perhitungan tersebut jalan Riau kota Pekanbaru, saat ini kategori tingkat pelayanannya $\mathrm{D}$ dengan karakteristik kondisi lalu lintas mencapai $1700 \mathrm{smp} / \mathrm{jam}, 1$ arah kecepatan lalu lintas berkisar $60 \mathrm{~km} / \mathrm{jam}$

Kondisi arus lalu lintas ini dipengaruhi oleh mulai meningkat nya volume lalu lintas Jalan Sudirman Kota Pekanbaru, yang diakibatkan oleh adanya tarikan yang terjadi pada ruas jalan Sudirman. tarikan pada ruas jalan Sudirman kota pekanbaru berupa Mall Pekanbaru dan Senapelan Plaza Sadira. Ada banyak hal yang menyebabkan keinginan masyarakat untuk datang ke ruas jalan Sudirman kota 
pekanbaru dengan adanya bangunan tersebut, mulai dari berbelanja kebutuhan sehari - hari, atau sebagai tempat hiburan seperti nonton bioskop, arena bermain keluarga seperti Timezone, tempat penginapan dan lain sebagainya. sehingga rentan terjadi nya permasalahan lalu lintas seperti kendaraan keluar masuk pusat perbelanjaan, pejalan kaki dan tingkah laku pemakai jalan yang tidak tertib yang menjadi salah satu faktor tingkat pelayanan jalan Sudirman kota pekanbaru.

\section{KESIMPULAN DAN SARAN}

\section{Kesimpulan}

Berdasarkan hasil analisis yang telah dilakukan, maka diperoleh kesimpulan pada tabel 5.1 dibawah ini.

Tabel 5.1 Indeks evaluasi tingkat pelayanan jalan Sudirman di depan Mall Pekanabru

\begin{tabular}{|c|l|l|}
\hline No & \multicolumn{1}{|c|}{ Uraian } & \multicolumn{1}{c|}{ Hasil } \\
\hline 1 & $\begin{array}{l}\text { Indeks tingkat } \\
\text { pelayanan }\end{array}$ & $\begin{array}{l}\text { D arus mendekati tidak stabil } \\
\text { Kecepatan lalu lintas turun } \\
\text { sampai 60 km/jam Volume lalu } \\
\text { lintas dapat mencapai 85\% dari } \\
\text { kapasitas (1700 smp perjam, } 2 \\
\text { arah) }\end{array}$ \\
\hline 2 & $\begin{array}{l}\text { Kecepatan arus bebas } \\
\text { kendaraan ringan (FV) }\end{array}$ & $54.421 \mathrm{~km} / \mathrm{jam}$ \\
\hline 3 & $\begin{array}{l}\text { Derajat kejenuhan } \\
\text { (DS) }\end{array}$ & 0.989 \\
\hline 4 & Kapasitas Jalan & $5.742 \mathrm{smp} / \mathrm{jam}$ \\
\hline
\end{tabular}

Sumber : Hasil perhitungan, 2017)

\section{Saran}

Saran yang bisa disampaikan pada kesempatan ini adalah :

1. Untuk mendapatkan karakteristik serta gambar derajat kejenuhan akibat pengaruh kecepatan serta indeks tingkat pelayanan untuk jalan Sudirman di depan Mall Pekanbaru yang lebih akurat, sebaiknya dilakukan peneletian lanjutan pada segmen-segmen lain diruas jalan ini.

2. Melakukan peningkatan kapasitas jalan, dalam hal ini peran aktif pemerintah daerah sangat diharapkan, mengingat volume lalu lintas pada jalan Sudirman di depan Mall Pekanbaru tidak sebanding lagi dengan kapasitas jalan pada saat ini.

3. Diperlukan kesadaran semua pihak khususnya pengguna jalan untuk menaati peraturan-peraturan lalu lintas yang berlaku di jalan tersebut.

\section{DAFTAR PUSTAKA}

[1] Badan Pusat Statistik. 2015. Pekanbaru Dalam Angka 2015. Pekanbaru. http://pekanbarukota.bps.go.id/index.php/publi kasi/4. (06 Maret 2017).

[2] Departemen Pekerjaan Umum. 1997. Manual Kapasitas Jalan Indonesia. Direktorat Jendral Bina Marga. http://repository.usu.ac.id/bitstream/12345678 9/1384/sipil-filiyanti5.pdf.txt. (06 Maret 2017).

[3] Dewan Perwakilan Daerah Republik Indonesia. 2004. UU No.38 Tahun 2004 Tentang Jalan. http://lansdpatial.bapppenas.go.id/peraturan/th e file/UU No38-2004.pdf. . (09 Maret 2017)

[4] Dewan Perwakilan Daerah Republik Indonesia. 2009. UU No.22 Tahun 2009 Tentang Jalan. http://lansdpatial.bapppenas.go.id/peraturan/th e file/UU No22-2009.pdf. (08 Maret 2017)

[5] Nizam MT. 2016. Persepsi Masyarakat Tentang Alternatif Pemecahan Masalah Transportasi Di Jalan Riau Kota Pekanbaru. Jurnal Teknik Sipil Unaya 2: $1-2$.

[6] Nurdin M. 2013. Evaluasi Tikungan Di Ruas Jalan Dekso - Samigaluh Kabupaten Kulon Progo. Jurnal Teknik Sipil.

[7] Safitri Y. 2011. Analisis Derajat Kejenuhan Dan Tingkat Pelayanan Jalan H. Imam Munandar Kota Pekanbaru (Tugas Akhir). Pekanbaru: Universitas Lancang Kuning.

[8] Timboeleg JA. 2015. Pengaruh Hambatan Samping Terhadap Kinerja Pada Ruas Jalan Panjaitan (Kelenteng Ban Hing Kiong) Dengan Menggunakan Metode Mkji 1997. Jurnal Teknik Sipil Statik 3: 6.

[9] Wahyudi A. (2015). Analisis Derajat Kejenuhan Dan Tingkat Pelayanan Jalan Kaharudin Nasution Kota Pekanbaru (Tugas Akhir). Pekanbaru: Universitas Lancang Kuning. 